\title{
Circumcision; A Comparative Study Between ZACH Self-Locking Clamp \& Bone Cutter
}

\section{Zafar Ali Choudhry ${ }^{1}$, Muhammad Faisal Bilal Lodhi' ${ }^{2}$, Shaukat Ali ${ }^{3}$, Muhammad Saleem Iqbal ${ }^{4}$, Muhammad Usman $^{5}$, Muhammad Farhan Azeem ${ }^{6}$}

1 Professor, Department of Surgery, Vice Chancellor Faisalabad Medical University, Faisalabad Pakistan

1 Principal investigator

2 Professor, Department of Surgery, Faisalabad Medical University, Faisalabad Pakistan

2 Proof reading

3 Assistant Professor, Department of Surgery, Faisalabad Medical University, Faisalabad Pakistan

3 Data collection

4 Assistant Professor, Department of Surgery, Faisalabad Medical University, Faisalabad Pakistan

4 Results interpretation

5 Senior Registrar, Department of Surgery, Faisalabad Medical University, Faisalabad Pakistan

5 Statistical analysis

6 Post Graduate Resident, Department of Urology, Allied Hospital, Faisalabad Pakistan

6 Data collection, Reference writing

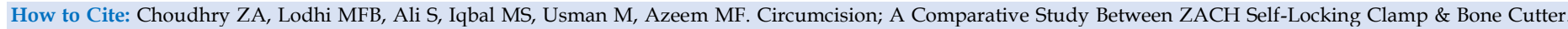
APMC 2021;15(1):6-8. DOI: 10.29054/APMC/2021.1104

\section{ABSTRACT}

Background: The circumcision has been performed for religious, ethnic and medical response. In Pakistan $85 \%-90 \%$ of circumcisions are performed by traditional circumcisers. The surgical technique for circumcision involves traditional bone cutter. Objective: To compare the results of one of the most commonly performed surgical procedure, circumcision, by bone cutter and ZACH self-locking circumcision clamp method in terms of complications such as trauma to glans, bleeding and infection along with cosmetic outcome. Study Design: Randomized control trial. Settings: Department of Surgery in Allied Hospital, Faisalabad Pakistan. Duration: September 2018 to November 2019. Methodology: Total 160 patients were selected from OPD on the basis of non-probability consecutive sampling. After careful history taking and physical examination, patients fulfilling the criteria were identified into two equal groups, one underwent circumcision with Bone Cutter and the other with Zach self-locking circumcision clamp. Parents were instructed to follow up in the surgical OPD after seven days for assessment and earlier in case of any complication. Results: There was significant difference in terms of bleeding, superficial infection, cosmetic appearance and trauma to glans ( $\mathrm{P}$-value $>0.05$ ). Conclusion: Zach self-locking clamp proved to be safe and effective technique with reproducible results as compared to bone cutter.

Keywords: Circumcision, Zach self-locking clamp, Bone Cutter, Cosmetic outcome, Hemorrhage.

\section{INTRODUCTION}

Despite as estimated one-sixth of the world's men having been circumcised, ${ }^{1,2}$ it has long been forgotten when or why this most intriguing operation began. ${ }^{3}$ The procedure has been performed for religious, ethnic and medical response, although the last has only become fashionable since the advancement of modern surgery in the $19^{\text {th }}$ century. ${ }^{4}$ In Pakistan $85 \%-90 \%{ }^{5}$ of circumcisions are performed by traditional circumcisers, village barbers, paramedical theatre staff and technicians where operation is performed with no anesthesia, no sutures, with unsterilized instruments and ashes of burnt wood are used to establish homeostasis, and only 10\%-15\% have access to a proper medical facility where a doctor performs the circumcision under strict aseptic technique. There is not a single study conducted, to compare the results of different methods, either locally or internationally. So out of number of surgical techniques; two methods were selected to compare the results in terms of complications such as trauma to the glans, bleeding and infection along with cosmetic outcome.

\section{METHODOLOGY}

Study Design: Comparative study.

Settings: Department of Surgery in Allied Hospital, Faisalabad Pakistan.

Duration: One year and three months from September 2018 to November 2019.

Sample Technique: Non-probability consecutive sampling technique.

Sample Size: One hundred Sixty patients were selected from the out-patients department for elective circumcision.

Inclusion Criteria: All healthy male patients, up to 1 year of age, undergoing circumcision only for ritual purpose were included. 
Exclusion Criteria: Congenital urogenital anomalies, severe neonatal jaundice or moribund conditions and deranged coagulation profile were excluded.

Data Collection Procedure: They were distributed into two equal groups $(n=80)$. Each patient assigned a random a random computer-generated number and was subjected to the following investigations, $\mathrm{Hb} \%$ and PT/APTT. Lignocaine $2 \%$ without adrenaline was infiltrated locally as a ring block round the base of penis in a dose of $1 \mathrm{Mg} / \mathrm{kg}$ of body weight to provide local anesthesia.

In one group, circumcision was done by Zach self-locking circumcision clamp. The prepuce was first fully retracted to expose the coronal sulcus and retained smegma removed. The tip of the prepuce was then grasped with two artery forceps and pulled forward over the glans with the light traction. Then Zach self- locking circumcision clamp was placed obliquely across the prepuce \& distal to the clamp prepuce cut with the knife. Clamp was released. In second group the tip of the prepuce was then grasped with two artery forceps and pulled forward over the glance with light traction. Then bone cutter was placed obliquely across the prepuce distal to the glance and parallel to the corona and the prepuce then divided immediately distal to the clamp with the knife. Clamp was released and inner layer of prepuce was trimmed accordingly. In both methods hemostasis was secured with absorbable $4 / 0$ plain catgut with especial attention to frenular vessels.

Postoperatively wound was dressed with a thin layer of Vaseline gauze and dry dressing for twenty-four hours. Parents were advised to start Sitz bath (Lukewarm water with few drops of Dettol solution in it) from next morning, twice daily for one week and let the dressing be off at its own. Syrup Calpol (paracetamol) was advised as analgesic in accordance with the age of the child. Patients were followed up in the surgical OPD after seven days for assessment and earlier in case of any complications.

Statistically Analysis: Data had been entered and analyzed using SPSS version - 20. Paired t-test was applied to compare the groups and P-value $<0.05$ was considered significant.

\section{RESULTS}

Bleeding was considered significant when measures, more than simple application of pressure bandage, were required to control the bleeding postoperatively. It remained the commonest complication $18.8 \%$ with Bone Cutter and $8.8 \%$ with Zach self-locking circumcision clamp ( $p$-value $>0.05$ ). Percentage of patients suffered from local infection, was $21.3 \%$ with Bone Cutter circumcision and $7.5 \%$ with Zach self-locking circumcision clamp circumcision (P-value $>0.05$ ).

Percentage of parents who were unsatisfied with the appearance of glans was $2.5 \%$ with Bone Cutter and 1.3\% were with Zach self-locking circumcision lamp method.
(P-value $>0.05)$. Not a single case of trauma to the glans was found in the study (table.1)

Table 1: Zach self-locking circumcision clamp versus open procedures $(n=160)$

\begin{tabular}{|c|c|c|c|c|}
\hline Procedure & \multicolumn{4}{|c|}{ Results (\%) } \\
\hline Bleeding & Infection & $\begin{array}{c}\text { Trauma } \\
\text { to } \\
\text { Glance } \\
\text { penis }\end{array}$ & $\begin{array}{c}\text { Unsatisfactory } \\
\text { Appearance }\end{array}$ \\
\hline $\begin{array}{c}\text { Zach Self- } \\
\text { Locking } \\
\text { circumcision } \\
\text { clamp Method } \\
(=80)\end{array}$ & $7(8.8 \%)$ & $8(7.5 \%)$ & $0(0 \%)$ & $1(1.3 \%)$ \\
\hline $\begin{array}{c}\text { Bone cutter } \\
(\mathrm{n}=80)\end{array}$ & 15 & $6(21.3 \%)$ & $0(0 \%)$ & $2(2.5 \%)$ \\
\hline P-Value & 0.004 & 0.001 & & 0.320 \\
\hline
\end{tabular}

Figure 1: ZACH self-locking circumcision clamp

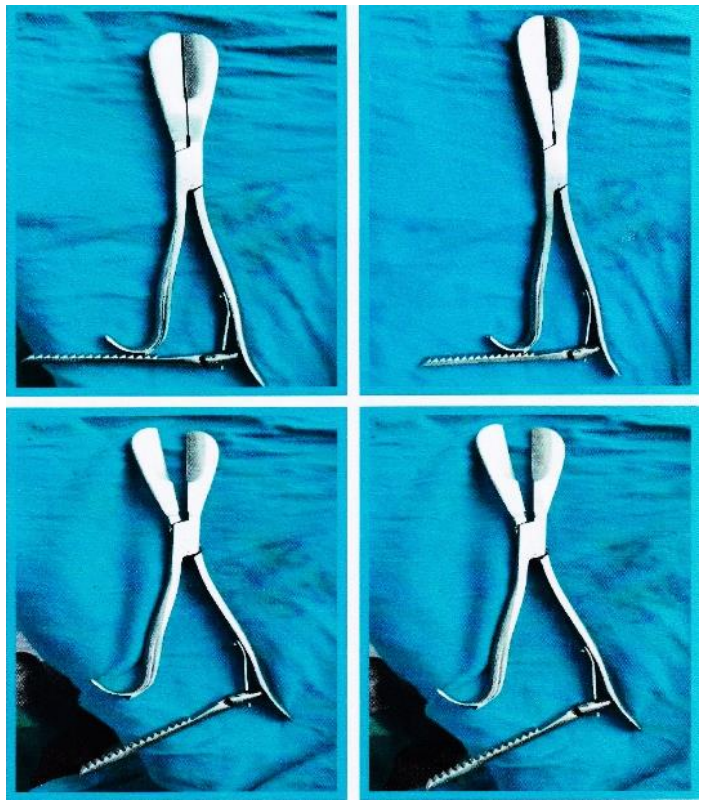

\section{DISCUSSION}

About one-sixth of the world's men undergo circumcision $^{1,2}$ for religious, or ethnic and medical reasons. In Pakistan, where 97\% population is Muslim by religion, every male has to undergo religious circumcision early in his life, Since long, it has been a common practice that circumcision is conducted by barbers under unhygienic conditions and despite obvious contra-indications. With improvement in literacy rate, the number of circumcisions being performed by the trained doctors is increasing. It is, therefore, of great importance to identify the best possible method of circumcision with minimum complications and satisfactory cosmetic outcome in our set up.

Bleeding occurred in $8.8 \%$ patients which remained slightly higher than studies described by Kapila et al ${ }^{6}$ and 
others ${ }^{7,8}$ while close to local studies. ${ }^{9-13}$ There is significant difference between the two procedures ( $\mathrm{P}=0.004)$. Superficial infection involving skin and mucosa was observed in 8 cases which remained slightly higher than the studies conducted local ${ }^{9,13}$ and abroad.6,8 $\mathrm{P}$-value $=$ 0.001. It was treated by oral antibiotic (syrup amoxicillin) and acetaminophen (syrup Calpol). There was not a single case of trauma to glans contradictory to studies conducted by Kaplan et al13 and Kapila et al. ${ }^{6}$ Overall the parents were satisfied with the cosmetic appearance of both methods $(\mathrm{P}=0.320)$. About $97 \%$ parents were satisfied as compared to $99 \%$ in a study by Amir M et al Study. ${ }^{9}$

\section{CONCLUSION}

There is significant difference present between the two procedures in terms of bleeding, infection, trauma to the glans and the cosmetic outcome. Zach self-locking clamp is surprise in terms of no need of assistance to hold the clamp as in the case of simple bone cutter.

\section{LIMITATIONS}

The sample size of the study was not large enough to predict that such result represents the true picture of complications.

\section{SUGGESTIONS / RECOMMENDATIONS}

Being a Muslim country, circumcision is one of the commonest elective surgical procedures in exact outcome of these procedures in our set up.
CONFLICT OF INTEREST / DISCLOSURE

No conflict of interest is involved.

\section{ACKNOWLEDGEMENTS}

We acknowledge hospital administration, patients and colleagues for helping to collect the data and doing the procedure.

\section{REFERENCES}

1. Moreno CA, Realini JP. Infant circumcision in an out-patient setting. Tex Med 1989, 8537-40.

2. Amir M, Raja MH, Naz WA. Neonatal circumcision with Gomco clamp-a hospital-based retrospective study of 1000 cases. J Pak Med Assoc 2000; 50(70: 224-7.

3. Rafiq K. Plastibel A quick technique to decrease the distress of neonatal circumcision. Ann King Edward Med Coll 2000;6:412-3.

4. "Male circumcision: Global trends and determinants of prevalence, safety and acceptability" (PDF). World Health Organization. 2007. Archived (PDF) from the original on 2015-12-22

5. Pieretti Rafael V, Goldstein Allan M, Pieretti Vanmarcke R. Late complications of newborn circumcision: a common and avoidable problem. Pediatr Surg Int. 2010;26:515-518

6. İnce B, Dadaci M, Altuntas Z, et al. Rarely seen complications of circumcision, and their management. Turk J Urol 2016;42:12-5.

7. Prabhakaran S, Ljuhar D, Coleman R, et al. Circumcision in the paediatric patient: a review of indications, technique and complications 2018;54:1299-307.

8. Ho TS, Gelman J. Evaluation and management of adult acquired buried penis. Transl Androl Urol 2018;7:618-27

9. Krill Aaron J, PALMER Lane S, PALMER Jeffrey S. Complications of circumcision. The Scientific World Journal 2011;11:2458-68.

10. Rafiq K. Plastibel A quick technique to decrease the distress of neonatal circumcision. Ann King Edward Med Coll 2000; 6:412-3.

11. Beg MAN. Circumcision using plastibel device. J Surg Pak 2000; 5:33.

12. Gondal KM, Ali A, Ranjha MA. Management of penile trauma. Ann King Edward Med Coll 2001; 7(1):47-9.

13. Kaplan GW. Complications of circumcision. Urol Clin North Am. 1983; 10: 543-9. 